\title{
Proceeding
}

Supplementary Issue: Rio 2016 Olympic Games Third Anniversary Special Edition. Olympic Studies Forum, 2-3 September

2019. Federal University of Sergipe, Aracaju, Brazil

\section{Trend to symptom-based depression in sub-elite and sports athletes}

\author{
DAIANNE CARDINALLI RÊGO ${ }^{1}$, AFRANIO DE ANDRADE-BASTOS ${ }^{1} \triangle$, DEBORAH LIMA RAMOS DE \\ MELO1, GRACIELLE COSTA REIS ${ }^{1,2}$, HORTENCIA MARIA SANTOS DE MELO1, ALLANA ANDRADE \\ SOUZA $^{1}$, AILTON FERNANDO SANTANA DE OLIVEIRA ${ }^{1}$ \\ ${ }^{1}$ Federal University of Sergipe, Brazil \\ 2 Tiradentes University, Brazil
}

\begin{abstract}
The prevalence of people in mental distress has increased in recent decades and has influenced the quality of life of the population. This work seeks to investigate the trend to depression based on symptoms in subelite athletes and athletes, enabling to illustrate the mental health situation of these populations. The study included 50 athletes and 30 sports athletes, 7 were female and 43 were male athletes, and 8 were women and 22 were men among the sports athletes. The instruments were used for the characterization of the sample containing items to do the profile and the Beck Depression Inventory II (BDI-II). The Mann-Whitney $U$ test for the Beck Depression Inventory among athletes and sub-elite athletes showed the lowest prevalence of symptoms among them $(U=495.5, p=.011)$. When comparing by gender $[F(1.75)=1.144, p=.288]$ and by age $[F(2.75)=.160, p=.852]$, there was no statistical difference between groups. The difference was perceived regarding the trend according to the cutoff points of BDI-II. For gender and age, all athletes, except for males, showed a slight trend and in all cases, athletes were classified with minimal trend. Athletes have a minimal trend, being less vulnerable to depression than sports athletes. depression Collective sports athletes were less vulnerable than individual athletes and sportsmen, and the athlete status was associated and correlated with the trend toward symptom-based. Keywords: Depression; Sport; Sub-elite athletes.
\end{abstract}

Cite this article as:

Rêgo, D.C., de Andrade-Bastos, A., de Melo, D.L.R., Reis, G.C., de Melo, H.M.S., Souza, A.A., \& de Oliveira, A.F.S. (2020). Trend to symptom-based depression in sub-elite and sports athletes. Journal of Human Sport and Exercise, 15(1proc), S11-S22. doi:https://doi.org/10.14198//hse.2020.15.Proc1.02

Corresponding author. Departamento de Educação Física, Av. Marechal Rondon, SN.49100-000. São Cristóvão, Sergipe, Brasil.

E-mail:afranioufs@gmail.com

Supplementary Issue: Rio 2016 Olympic Games Third Anniversary Special Edition. Olympic Studies Forum, 2-3 September 2019. Federal University of Sergipe, Aracaju, Brazil.

JOURNAL OF HUMAN SPORT \& EXERCISE ISSN 1988-5202

(c) Faculty of Education. University of Alicante

doi:10.14198/jhse.2020.15.Proc1.02 


\section{INTRODUCTION}

The advertising of mental suffering cases in elite athletes by the media, especially in the last Olympic games, has highlighted psychological well-being in the sporting and scientific interest (Nixdorf et al., 2013). In the last decades, the prevalence of mental suffering people has increased, and this suffering has promoted a great influence on the quality of life and the daily life of the population (Schmidt et al., 2011). Depression is the most common disorder in the world population (Andrade et al., 2003; Patel et al., 2016), and this disorder among elite athletes, especially the Olympics, is also quite prevalent (Beable et al., 2017; Brand et al. Gulliver et al., 2015, Du Preez et al., 2017). Some studies comparing this population and non-athletes show that highperformance athletes, this also includes the Olympians, are prone to presenting depressive symptoms as non-athletes (Bar and Markser, 2013; L Ghaedi et al., 2014; Junge and Feddermann-Demont, 2016; Schaal et al. ., 2011; Wolanin et al., 2015). However, there are studies suggesting that university athletes have a lower incidence of symptoms than non-athletes (Armstrong and Early, 2009; Proctor and Boan-Lenzo, 2010). These findings show the lack of knowledge if athletes are less prone to depression than non-athletes (Nixdorf et al., 2013).

It is clear that regular physical activity improves the symptomatology of depression (Dunn et al., 2005, 2002; Stanton and Reaburn, 2014). Some studies seek to understand how the exercise intensity interferes with this improvement (Danielsson et al., 2014; Meyer et al., 2016; Schuch et al., 2017, 2016, 2011) because previous studies have shown that mood worsens with an intensephysical activity(Blanchard et al., 2001; O'Connor et al., 1991; Oweis e Spinks, 2001). Since elite athletes undergo extensive training loads, this would be a possible implication for the high prevalence of depression in this population. Thus, it is extremely important to understand if these evidences are also perceived in sub-elite athletes. Elite athletes are the individuals who represent the country internationally, reaching the podium in these competitions and/or playing at the highest levels of professional competition, being part of the official ranking among the 100 best athletes (Gulbin et al., 2013), having its greatest reference the Olympic and World Champions. Elite athletes face many factors causing depression (body image, competitiveness, loss of sponsors) (Gulliver et al., 2009), and even their position of being an elite athlete (Hughes e Leavey, 2012). Subelite athletes may present different tendencies to depression since they are exposed to different stressors at each competitive level.

Another important issue is the comparison of these sub-elite athletes with sports athletes. They represent the group of individuals who improve their movements, learn about the pillars of the sport and the specific characteristics of it, with leisure function and improvement of physical fitness. This comparison seeks to understand if the recreational sports practice promotes a difference in the trend towards the population depression. Previous studies comparing athletes and non-athletes disregarded the practice of leisure sports as a variable in the non-athlete sample.

Understanding that the principles of Olympism presented by Pierre de Coubertin understood the practice of amateur sports with a broad and educational vision, therefore, for all, this work seeks to investigate the trend to depression based on symptoms in sub-elite athletes and athletes, enabling to illustrate the mental health situation of these populations.

\section{METHODS}

\section{Participants}

The research was composed of two groups, the first group with athletes and the second group with sports athletes. Their participation was voluntary, and the individuals should be 17 years old or over; be a sub-elite 
athlete participating in competitions in 2016 and/or 2017; and be a sportsman in the respective period. The study included 50 athletes and 30 sports athletes, 7 were female and 43 were male athletes, and 8 were women and 22 were men among the sports athletes.

\section{Instruments}

The instruments were used for the characterization of the sample containing items to do the profile and the Beck Depression Inventory II (BDI-II). The BDI-II is composed of 21 groups of statements, with answers between 0 and 3 , with the value associated with the intensity of the symptom measured (Steer et al., 1999). The result of the test is given by the sum of the affirmative statements, which can vary from 0 to 63 , divided into 4 trend levels: with a score of 0 to 9 , it is classified with a minimum trend, between 10 and 18, with a slight trend, 19 to 29, moderate and from 30 to 63, with a severe trend to depression (Beck et al., 2011).

\section{Design and Procedures}

This is an exploratory, descriptive, analytical, cross-sectional and quantitative research, developed in Sergipe, Brazil. It was submitted and approved by the Ethics and Research Committee, under number $2,203,861$, and carried out between April and July 2017. The athletes were sought in gyms in the city of Aracaju and the metropolitan region. Some athletes were invited after direct contact or indication of coaches. The representatives of the non-athlete population were randomly approached in public places and with great circulation of people.

The individuals were invited and accepted to participate, they signed the Informed Consent Term, which led to the filling of the instruments only once, avoiding promoting biased results by repeated applications. Some participants collaborated individually, answering their instruments in environments with more participants, but without the contribution of the group.

\section{Statistical analysis}

Statistical software SPSS version 23 was used for the Mann-Whitney $U$ test, of the Multiple variance analysis (ANOVA factorial) with Bonferroni post-test analysis and Pearson's Chi-square association and Spearman correlation. The BDI-II score was considered as an outcome variable, analysed from the fixed independent variable sport practice, in comparison with the independent variables: gender, age, competitive activity time, level of competition, receipt of financial aid, type of sport and training time. Statistically, significant difference was considered when $p<.05$.

\section{RESULTS}

The Mann-Whitney $U$ test for the Beck Depression Inventory among athletes and sub-elite athletes showed the lowest prevalence of symptoms among them $(U=495.5, p=.011)$. Table 1 shows sample data.

When comparing by gender (Figure $2 A)[F(1.75)=1.144, p=.288]$ and by age (Figure $2 B$ ) $[F(2.75)=.160$, $p=.852]$, there was no statistical difference between groups. The difference was perceived regarding the trend according to the cut-off points of BDI-II. For gender and age, all athletes, except for males, showed a slight trend and in all cases, athletes were classified with minimal trend.

When comparing athletes and sub-elite athletes divided by competition levels (Figure 3A), there is no statistical difference between the groups $[F(4.75)=2.667, p=.085]$, the difference is in the classification given by BDI-II, athletes with light trend and athletes of all levels of competition, minimum. 
Table1. Characterization of the sample.

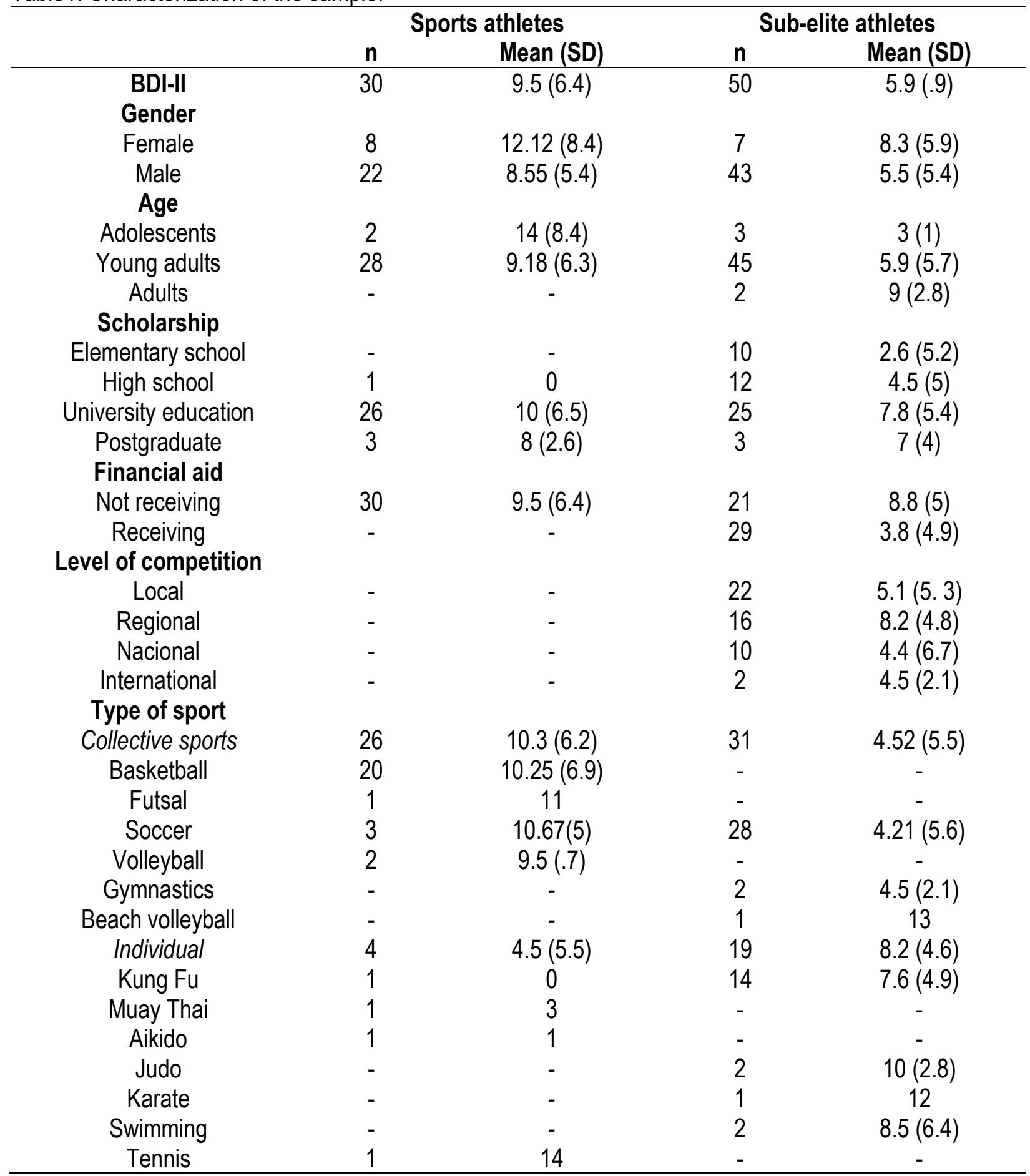

Figure 1 shows that most of the sub-elite athletes $(74 \%)$ were classified as having a minimal trend to depression, while $50 \%$ of non-athletes received this classification. 


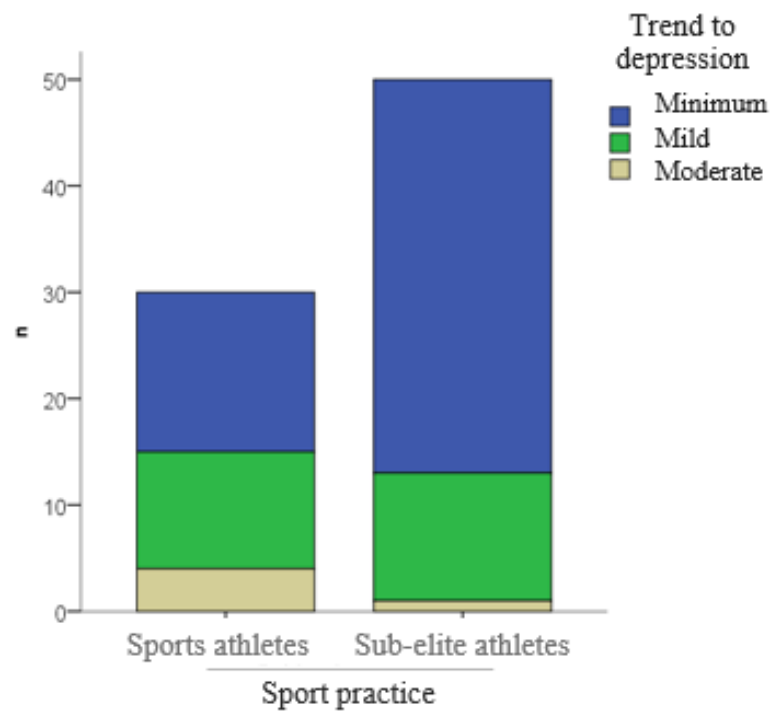

Figure 1. Distribution of the trend to depression in athletes and sub-elite athletes.
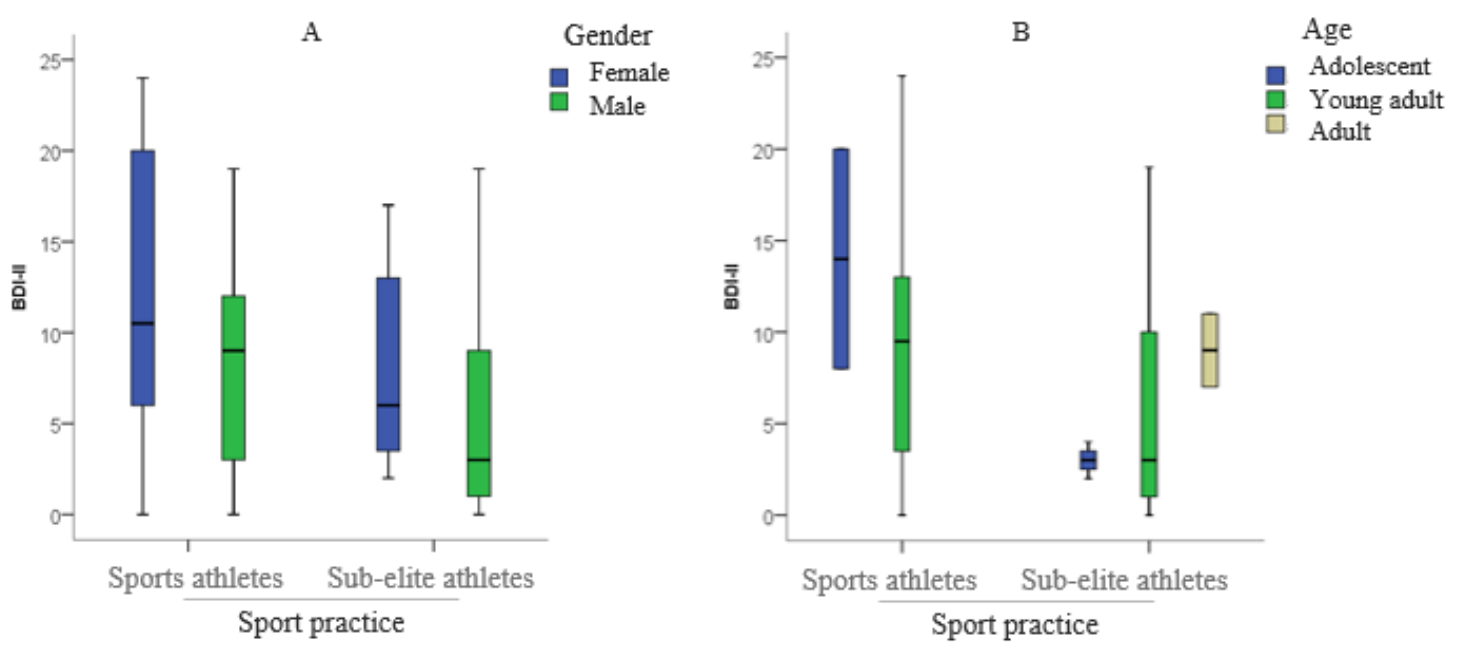

Figure 2. BDI-Il between athletes and sub-elite athletes by gender $(A)$ and age $(B)$.

When analysing the financial aid variable (Figure 3B), a statistically significant difference was observed in the sub-elite athlete group $[F(2.77)=8.856, p=.007]$ and between the athletes receiving and sports athletes $[F(2.77)=8,856, p=.001]$. Both cases show that athletes who receive money for the sport have fewer symptoms. This data is also evidenced by the category of Beck they were classified, athletes regardless of receiving financial aid were classified with minimal trend and sports athletes with mild trend.

In the comparison of competitive activity time, there were no differences between athletes $[F(2.77)=4.163$, $p=.796]$ and between athletes and sports athletes competing for at least 3 years $[F(2.77)=4.163, p=.731]$. Among athletes and sports athletes who competed for more than 4 years, athletes presented better results $[F(2.77)=4.163, p=.015]$. Sports athletes were classified with slight trend, the others with minimum trend. 
When observing the days training per week, there were no differences between athletes $[F(1.48)=.087$, $p=.770]$, sports athletes $[F(1.28)=2.584, p=.119]$, and between sports athletes and athletes $[F(1.38)=3.800$, $p=.613]$, regardless of the number of days per week. The difference was limited to the categories of BDI-II, evidencing only sports athletes who train up to 3 days per week were characterized with a slight trend.
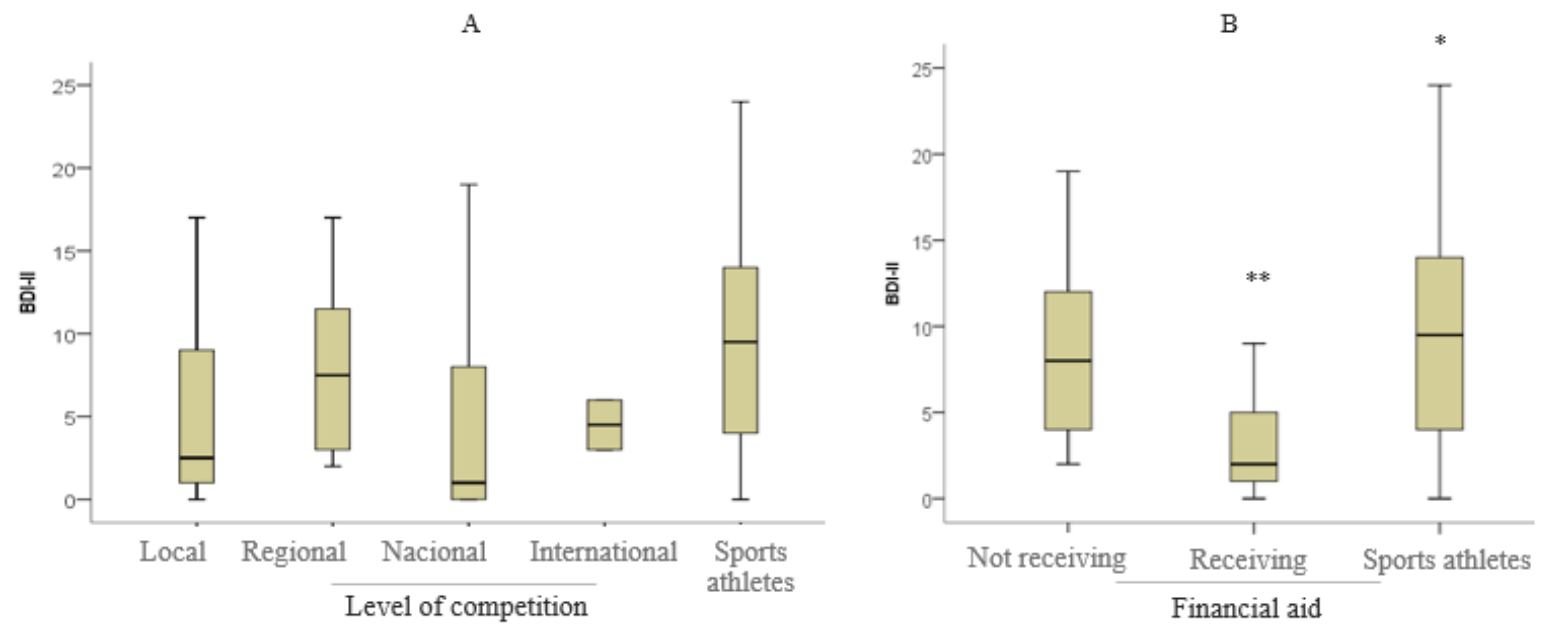

Note: ${ }^{*}$ is the difference within the group of sub-elite athletes (between who receives and who does not), ${ }^{*}$ difference between sports athletes and athletes who receive financial aid.

Figure 3. BDI-II between sports athletes and sub-elite athletes by level of competition(A)and financial aid (B).

In the analysis performed using the type of sport practiced as a variable, there was no statistical difference within the group of sports athletes, $[F(1.28)=2.997, p=.094]$, there was difference within the group of athletes $[F(1.55)=5.905, p=.019]$, with better results for team sports. The sub-elite athletes of team sports presented better results than collective sports athletes $[F(1.55)=13.759, p<.001]$, as well as there was no difference when individuals were involved in individual sports $[F(1.21)=1.858, p=.187]$. Regarding the classification of the BDI-II, sub-elite athletes of collective and individual sports and individual sports athletes obtained results that classify them with minimal trend, that is, without vulnerability to the disease. It is important to note that $56 \%$ of the participants in the study are soccer players, corresponding to $90.3 \%$ of the category of collective sports athletes.

Analysing the data using the Chi-square between sport practice and BDI-II categories, it can be observed that there was an association between the variables, $x 2(4)=20.505(p<.001)$. For the Spearman correlation analysis, ars=-. 418 was found to be indirectly moderate.

\section{DISCUSSION}

Studies have already pointed to the idea that being physically active and involved in sports decreases the onset of depressive symptoms (Danielsson et al., 2014; McDowell et al., 2017; McKercher et al., 2009; Nixdorf et al., 2013, Oja et al., 2006, Peluso and Andrade, 2005, Ströhle et al., 2007). However, there is no research that points to differences in the intensity of these symptoms between athletes and sub-elite athletes. Studies that analyse this phenomenon in athletes do it with elite athletes and considered the comparative population only as non-athlete, not considering whether or not they practice sports or physical exercise. Proctor and Boan-Lenzo (2010) and Armstrong and Early (2009) for example reported a prevalence of lower 
depression symptoms in elite athletes than in non-athletes. Fahim Devin et al. (2015), Frank et al. (2013) and Gorczynski et al. (Gorczynski et al., 2017) found higher prevalence in athletes.

Considering these assumptions, the results that indicate better results in sub-elite athletes may be related to the condition of not being part of the elite and to the competitiveness of the routine of these athletes. Both sub-elite athletes and sports athletes practice sports and exercise as a routine, the main difference between them is the purpose of the practice. Sports athletes seek self-realization associated with the improvement of sports skills (Bernardes et al., 2015), as well as better quality of life or appearance. Subelite athletes seek to improve skills and abilities inherent in competitive practice to reach other competitive levels. Exercise practiced for a competitive purpose seems to be more beneficial in protecting against symptoms of depression.

This aspect may have been enhanced by the competitiveness in the routine of sub-elite athletes, a competitiveness that seems to be less damaging than in elite athletes. Competition can be an important point for competitive sport adherence, as it predicts the willingness to compete among the participants (Halko and Sääksvuori, 2017), as well as being challenging to improve individuals' self-confidence (North et al. , 1990), facilitating the search for new objectives and better results by comparison with the results of the competitors. Thus, even though both groups practice daily sports and exercise (an important factor for reducing vulnerability to depression), athletes have competitiveness as a necessary quality to obtain a sporting performance (Sebastian et al., 2002), being potentially protective of mental health.

Another aspect to be observed is that supervised sports practice by a specialized professional is associated with significant decreases in depression symptoms (Schuch et al., 2017, 2016, Ward et al., 2015). It is common the practice of physical exercise and sports by sports athletes only with friends, without professional supervision. Subelite athletes usually have multi-professional monitoring for the improvement of the performance in the championships.

Although they did not have a statistical difference, when comparing women between the groups, the BDI-II values showed a minimal trend in athletes and a slight trend in sports athletes. Also, women athletes had 1point difference to change the classification, a value almost equal than sports athletes. This finding corroborates with investigations that women are more affected by symptoms of depression than men (Hoebel et al., 2017, Junge and Feddermann-Demont, 2016, Storch et al., 2005), including among athletes (Covassin et al., Gorczynski et al., 2017, Yang et al., 2007). This evidence is possibly given by men having more difficulty or feeling more repressed in expressing their emotions (Rao and Hong, 2015).

From the point of view of their age, even though it is not statistically significant, the numerical difference among adolescents is 11 points, showing that competitiveness in adolescence can be an effective strategy for protection against mental suffering. Thus, only practicing sports can be more beneficial for young adults, seeing a difference of almost 5 points between adolescent sports athletes and young adults. It may be related to the biological and emotional maturity of the young adult, differently from the adolescent. Therefore, being active and being involved in sports without a competitive purpose can be a lower level of depressive symptoms among athletes and may protect against the development of the disease (Ströhle et al., 2007). However, competitiveness, common to sub-elite athletes, has proved to be more beneficial for adolescents. This benefit may also be related to the sports practiced by the sample, where a study pointed out that the symptoms of depression were more evident in aesthetic athletes (Schaal et al., 2011). 
Financial security is perceived as an element capable of protecting athletes against mental suffering (Junge and Feddermann-Demont, 2016; Mammen and Faulkner, 2013). Subelite athletes seem to lack of financial aid as a major stressor for the development of mental distress. Gulliver et al. (2015) realized that the salary among elite athletes was considered a major stressor. The benefits of receiving financial aid may be related to the findings of Bucciol et al. (2014) who found a positive match between payment and performance, as well as Hoebel et al. (2017) who noticed an inversely proportional association between payment and depressive symptoms. This evidence demonstrates why athletes and sub-elite athletes who do not receive financial aid are different between them.

A recent study by Harvey et al. (2017) shows that only 1 hour of exercise per week is enough to protect individuals against depression. This may explain why there were no statistical differences between the groups, regardless of the number of training days and the time of competitive activity. Therefore, it is understood that the practice of sports and exercises benefits the individual regardless of their time of exposure to practice.

The literature highlights the collectivity as an element that benefits individuals' mental health (Nixdorf et al., 2016; Wolanin et al., 2016). When there are teammates, the individual can divide the conflicts and the results (Alloy et al., 2006; Hanrahan and Cerin, 2009), experiencing less stressful events alone. In this research, it was possible to notice that among sub-elite athletes this finding is repeated; Athletes of collective sports show lower intensity of depression symptoms, demonstrating absence of vulnerability. However, individual sports have allowed better results in the evaluation of mental suffering than those who only play sports, although it was not a statistically significant improvement since they were classified with minimal trend. This finding may be associated with the great presence of university students among the collective sports athletes (26 university students in the 30 sports athletes), since university students are more likely to present symptoms of depression than the general population (Alfaris et al., 2016; et al., 2016; Oyekcina et al., 2018).

The association shows that there is a relationship between being a sub-elite athlete and the symptoms of depression, and the moderate correlation showed that this relationship is between being an athlete and having a lower trend to disease. However, this result does not corroborate with the literature (Leila Ghaedi et al., 2014; Gorczynski et al., 2017; Kaier et al., 2015; Mohammadi et al., 2011). This difference may be related to non-elite athletes. Being sub-elite athlete can be an important aspect for not developing symptoms of depression.

\section{CONCLUSION}

Athletes have a minimal trend, being less vulnerable to depression than sports athletes. Also, those who receive salary/financial aid have lower intensity of symptoms than athletes and sports athletes who do not receive this benefit. Collective sports athletes were less vulnerable than individual athletes and sportsmen, and the athlete status was associated and correlated with the trend toward symptom-based depression.

\section{REFERENCES}

Alfaris E, Irfan F, Qureshi R, Naeem N, Alshomrani A, Ponnamperuma G, Al Yousufi N, Al Maflehi N, Al Naami, Jamal A \& van der Vleuten C. (2016) Health professions' students have an alarming prevalence of depressive symptoms : exploration of the associated factors. BMC Med Educ;16:1-8. https://doi.org/10.1186/s12909-016-0794-y 
Alloy L, Abramson L, Whitehouse W, Hogan M, Panzarella C \& Rose D. (2006) Prospective incidence of first onsets and recurrences of depression in individuals at high and low cognitive risk for depression. J Abnorm Psychol;115:145-56. https://doi.org/10.1037/0021-843x.115.1.145

Andrade L, Caraveo-anduaga JJ, Berglund P, Bijl R V., Graaf R De, Vollebergh W, Dragomirecka E, Kohn R, Keller M, Kessler RC, Kawakami N, Kiliç C, Offord D, Ustun TB \& Wittchen HU.. (2003) The epidemiology of major depressive episodes: (ICPE), results from the International Consortium of Psychiatric Epidemiology Surveys. Int $\mathrm{J}$ Methods Psychiatr Res;12:3-21. https://doi.org/10.1002/mpr.138

Appaneal RN, Levine BR, Perna FM \& Roh JL. (2009) Measuring postinjury depression among male and female competitive athletes. J Sport Exerc Psychol;31:60-76. https://doi.org/10.1123/jsep.31.1.60

Armstrong S \& Early JO. (2009) Social Connectedness, Self-Esteem, and Depression Symptomatology Among Collegiate Athletes Versus Nonathletes. J Am Coll Heal. https://doi.org/10.3200/jach.57.5.521-526

Bar K \& Markser V. (2013) Sport specificity of mental disorders: the issue of sport psychiatry. Eur Arch Psychiatry Clin Neurosci;263:S205-10. https://doi.org/10.1007/s00406-013-0458-4

Beable S, Fulcher M, Lee AC \& Hamilton B. (2017) SHARP - Sports mental Health Awareness Research Project Prevalence and Risk Factors of Depressive Symptoms and Life Stress in Elite Athletes.pdf. J Sci Med Sport;51:2-20. https://doi.org/10.1136/bjsports-2016-097372.25

Beck A, Steer R\& Brown G. (2011) BDI-II - Inventário de Depressão de Beck. São Paulo: Casa do Psicólogo.

Bernardes AG, Yamaji BHS\& Guedes DP. (2015) Motivos para prática de esporte em idades jovens: Um estudo de revisão. Motricidade;11:163-73. https://doi.org/10.6063/motricidade.3066

Blanchard C, Rodgers W, Spence J \& Courneya K. (2001) Feeling state responses to acute exercise of high and low intensity. J Sci Med Sport;4:30-8.

Brand R, Wolff W \& Hoyer J. (2013) Psychological Symptoms and Chronic Mood in Representative Samples of Elite Student-Athletes, Deselected Student-Athletes and Comparison Students. School Ment Health;5:166-74. https://doi.org/10.1007/s12310-012-9095-8

Bucciol A, Foss NJ \& Piovesan M. (2014) Pay Dispersion and Performance in Teams. PLoS One;9:116. https://doi.org/10.1371/journal.pone.0112631

Covassin T, III RJE, Larson E \& Kontos AP. (2012) Sex and Age Differences in Depression and Baseline Sport-Related Concussion Neurocognitive Performance and Symptoms. Clin J Sport Med;22:98104. https://doi.org/10.1097/jsm.0b013e31823403d2

Danielsson L, Papoulias I, Petersson EL, Carlsson J \& Waern M. (2014) Exercise or basic body awareness therapy as add-on treatment for major depression: A controlled study. J Affect Disord;168:98-106. https://doi.org/10.1016/j.jad.2014.06.049

Dunn AL, Trivedi MH, Kampert JB, Clark CG \& Chambliss HO. (2005) Exercise treatment for depression: Efficacy and dose response. Am J Prev Med;28:1-8. https://doi.org/10.1016/j.amepre.2004.09.003

Dunn AL, Trivedi MH, Kampert JB, Clark CG \& Chambliss HO. (2002) The DOSE study: a clinical trial to examine efficacy and dose response of exercise as treatment for depression. Control Clin Trials;13:584-603. https://doi.org/10.1016/s0197-2456(02)00226-x

Fahim Devin H, Farbod D, Ghasabian H, Bidel T \& Ghahremanlou F. (2015) Comparative and Correlative Study of Psychological Hardiness and Competitiveness among Female Student Athletes in Individual and Team Sports. Sport Sci Rev;24:201-14. https://doi.org/10.1515/ssr-2015-0016

Frank R, Nixdorf I \& Beckmann J. (2013) Depression in Elite Athletes: Prevalence and Psychological Factors. Dtsch Z Sportmed;64:320-6.

Ghaedi L, Kosnin AM \& Mislan N. (2014) Comparison of the degree of depression between athletic and non- athletic undergraduate students. Open Sci J Educ;2:1-6. 
Gorczynski PF, Coyle M \& Gibson K. (2017) Depressive symptoms in high-performance athletes and non-athletes : a comparative meta-analysis. Br J Sports Med;0:1-8. https://doi.org/10.1136/bjsports2016-096455

Gulbin JP, Croser MJ, Morley EJ \& Weissensteiner J. (2013) An integrated framework for the optimisation of sport and athlete development: A practitioner approach. J Sports Sci;31:1319-31. https://doi.org/10.1080/02640414.2013.781661

Gulliver A, Griffiths KM, Mackinnon A, Batterham PJ \& Stanimirovic R. (2015) The mental health of Australian elite athletes. J Sci Med Sport;18:255-61. https://doi.org/10.1016/j.jsams.2014.04.006

Halko M-L \& Sääksvuori L. (2017) Competitive behavior, stress, and gender. J Econ Behav Organ;141:96-109. https://doi.org/10.1016/j.jebo.2017.06.014

Hanrahan S \& Cerin E. (2009) Gender, level of participation, and type of sport: differences in achievement goal orientation and attri2butional style. J Sci Med Sport;12:508-512. https://doi.org/10.1016/j.jsams.2008.01.005

Harvey SB, Øverland S, Hatch SL \& Wessely S. (2017) Exercise and the Prevention of Depression: Results of the HUNT Cohort Study. Am J Psychiatry:1-9. https://doi.org/10.1176/appi.ajp.2017.16111223

Hoebel J, Maske UE, Zeeb H \& Lampert T. (2017) Social Inequalities and Depressive Symptoms in Adults: The Role of Objective and Subjective Socioeconomic Status. PLoS One:1-18. https://doi.org/10.1371/journal.pone.0169764

Hughes L \& Leavey G. (2012) Setting the bar: athletes and vulnerability to mental illness. Br J Psychiatry;200:95-6. https://doi.org/10.1192/bjp.bp.111.095976

Junge A \& Feddermann-Demont N. (2016) Prevalence of depression and anxiety in top-level male and female football players. BMJ Open Sport Exerc Med;2:e000087. https://doi.org/10.1136/bmjsem2015-000087

Kaier E, Cromer LD, Johnson MD, Strunk K, Davis JL \& Demarni L. (2015) Perceptions of Mental IIIness Stigma: Comparisons of Athletes to Nonathlete Peers. J Coll Stud Dev;56:735-9. https://doi.org/10.1353/csd.2015.0079

Mammen G \& Faulkner G. (2013) Physical activity and the prevention of depression: a systematic review of prospective studies. Am J Prev Med;45:649-57.

McDowell CP, MacDonncha C \& Herring MP (2017). Brief report: Associations of physical activity with anxiety and depression symptoms and status among adolescents. J Adolesc;55:1-4. https://doi.org/10.1016/j.adolescence.2016.12.004

McKercher CM, Schmidt MD, Sanderson KA, Patton GC, Dwyer T \& Venn AJ. (2009) Physical Activity and Depression in Young Adults. Am J Prev Med;36:161-4. https://doi.org/10.1016/j.amepre.2008.09.036

Melese B, Bayu B, Wondwossen F, Tilahun K, Lema S \& Ayehu M. (2016) Prevalence of mental distress and associated factors among Hawassa University medical students, Southern Ethiopia : a cross sectional study. BMC Res Notes:1-7. https://doi.org/10.1186/s13104-016-2289-7

Meyer JD, Koltyn KF, Stegner AJ, Kim JS \& Cook DB. (2016) Influence of Exercise Intensity for Improving Depressed Mood in Depression: A Dose-Response Study. Behav Ther;47:527-37. https://doi.org/10.1016/j.beth.2016.04.003

Mohammadi A, Kiyani R, Araghi R \& Zamini S. (2011) Social and The compare of depression between athlete and non-athlete employed people. Procedia - Soc Behav Sci;30:1878-80. https://doi.org/10.1016/i.sbspro.2011.10.365

Nixdorf I, Frank R \& Beckmann J. (2016) Comparison of Athletes ' Proneness to Depressive Symptoms in Individual and Team Sports : Research on Psychological Mediators in Junior Elite Athletes. Front Psychol;7:1-8. https://doi.org/10.3389/fpsyg.2016.00893 
Nixdorf I, Hautzinger M \& Beckmann J. (2013) Prevalence of depressive symptoms and correlating variables among German elite athletes. J Clin Sport Psychol;7:313-26. https://doi.org/10.1123/jcsp.7.4.313

North T, McCullagh P \& Tran Z. (1990) Effect of exercise on depression. Exerc Sport Sci Rev;18:379415.

O'Connor P, Morgan W \& Raglin J. (1991) Psychobiologic effects of $3 \mathrm{~d}$ of increased training in female and male swimmers. Med Sci Sports Exerc;23:1055-61.

Oja P, Titze S, Kokko S, Kujala UM, Heinonen A, Kelly P, Koski P \& Foster C.. (2015) Health benefits of different sport disciplines for adults: systematic review of observational and intervention studies with meta-analysis. Br J Sports Med;49:434-40. https://doi.org/10.1136/bjsports-2014-093885

Oweis P \& Spinks W. (2001) Biopsychological, affective and cognitive responses to acute physical activity. J Sport Med Phys Fitnes;41:528-38.

Oyekcina DG, Sahinb EM \& Aldemirc E. (2018) Mental health , suicidality and hopelessness among university students in. Asian J Psychiatr;29:185-9. https://doi.org/10.1016/i.ajp.2017.06.007

Patel V, Chisholm D, Parikh R, Charlson FJ, Degenhardt L, Dua T, et al. (2016) Addressing the burden of mental, neurological, and substance use disorders: key messages from Disease Control Priorities, 3rd edition. Lancet;387:1672-85. https://doi.org/10.1016/s0140-6736(15)00390-6

Peluso MAM \& Andrade LHSG de. (2005) Physical activity and mental health: the association between exercise and mood. Clinics;60:61-70. https://doi.org/10.1590/s1807-59322005000100012

Du Preez EJ, Graham KS, Gan TY, Moses B, Ball C \& Kuah DE. (2017) Depression, Anxiety, and Alcohol Use in Elite Rugby League Players Over a Competitive Season. Clin J Sport Med. https://doi.org/10.1097//sm.0000000000000411

Proctor SL \& Boan-Lenzo C. (2010) Prevalence of depressive symptoms in male intercollegiate studentathletes and nonathletes. J Clin Sport Psychol;4:204-2220. https://doi.org/10.1123/icsp.4.3.204

Rao AL \& Hong ES. (2015) Understanding depression and suicide in college athletes: emerging concepts and future directions. Br J Sports Med;0:2-5. https://doi.org/10.1136/bjsports-2015-095658

Schaal K, Tafflet M, Nassif H, Thibault V, Pichard C, Alcotte M, Guillet T, El Helou N, Berthelot G, Simon S \& Toussaint JF. (2011) Psychological Balance in High Level Athletes: Gender-Based Differences and Sport-Specific Patterns. PLoS One;6:1-9. https://doi.org/10.1371/journal.pone.0019007

Schmidt DR, Dantas RA \& Marziale MH. (2011) Ansiedade e depressão entre profissionais de enfermagem que atuam em blocos cirúrgicos. Rev da Esc Enferm da USP;45:487-93. https://doi.org/10.1590/s0080-62342011000200026

Schuch FB, Vancampfort D, Richards J, Rosenbaum S, Ward PB \& Stubbs B. (2017) Exercise as a treatment for depression : A meta - analysis adjusting for publication bias . J Psychiatr Res;77:4251. https://doi.org/10.1016/j.jpsychires.2016.02.023

Schuch FB, Vasconcelos-Moreno MP, Borowsky C \& Fleck MP. (2011) Exercise and severe depression: Preliminary results of an add-on study. J Affect Disord;133:615-8. https://doi.org/10.1016/i.jad.2011.04.030

Sebastian S, Gallegos O, Simões AC, Prouvot P de A \&Yoshikawa RMS. (2002) Competitividade e performance esportiva em tenistas profissionais. Rev Paul Educ Física;16:144-59.

Stanton R \& Reaburn P. (2014) Exercise and the treatment of depression: A review of the exercise program variables. J Sci Med Sport;17:177-82. https://doi.org/10.1016/j.jsams.2013.03.010

Steer R, Ball R, Ranieri W \& Beck A. (1999) Dimensions of the Beck Depression Inventory-II in clinically depressed outpatients. J Clin Psychol;55:117-28. https://doi.org/10.1002/(sici)10974679(199901)55:1<117::aid-jclp12>3.0.c0;2-a 
Storch E A., Storch JB, Killiany EM, Roberti JW. (2005) Self-Reported Psychopathology in Athletes: A Comparison of Intercollegiate Student-Athletes and Non-Athletes. J Sport Behav;28:86-98. https://doi.org/10.1023/b:pasp.0000031527.02433.5b

Ströhle A, Hofler M, Pfister H, Muller A-G, Hoyer J, Wittchen H-U \& Lieb R. (2007) Physical activity and prevalence and incidence of mental disorders in adolescents and young adults. Psychol Med;37:1657-1666. https://doi.org/10.1017/s003329170700089x

Ward MC, White DT \& Druss BG. (2015) A meta-review of lifestyle interventions For, for cardiovascular risk factors in the general medical population: lessons individuals with serious mental illness. J Clin Psychiatry;762:477-86. https://doi.org/10.4088/jcp.13r08657

Wolanin A, Gross M \& Hong E. (2015) Depression in Athletes: Prevalence and Risk Factors. Am Coll Sport Med;14:56-60.

Wolanin A, Hong E, Marks D, Panchoo K, \& Gross M. (2016) Prevalence of clinically elevated depressive symptoms in college athletes and differences by gender and sport. Br J Sports Med;50:167-71. https://doi.org/10.1136/bjsports-2015-095756

Yang J, Peek-Asa C, Corlette JD, Cheng G, Foster DT \& Albright J. (2007) Prevalence of and risk factors associated with symptoms of depression in competitive collegiate student athletes. Clin J Sport Med;17:481-487. https://doi.org/10.1097/jsm.0b013e31815aed6b

\section{@(@) $\Theta \Theta$}

This work is licensed under a Attribution-NonCommercial-NoDerivatives 4.0 International (CC BY-NC-ND 4.0). 